\title{
Doença mão-pé-boca no adulto: apresentação típica em idade atípica
}

Mara Arruda, ${ }^{1}$ Daniela Pacheco, ${ }^{2}$ Joana Meneses, ${ }^{3}$ Maria Rita Mota, ${ }^{2}$ Rita Santa Comba ${ }^{3}$

\section{RESUMO}

Introdução: A doença mão-pé-boca (DMPB) é uma infeção aguda autolimitada, altamente contagiosa, de etiologia vírica, que ocorre sobretudo em crianças. O quadro clínico típico caracteriza-se pelo aparecimento de um enantema oral doloroso, seguido de lesões cutâneas nas palmas das mãos e plantas dos pés, de morfologia, tamanho e cor variáveis. O seu diagnóstico é sobretudo clínico, o tratamento sintomático e o prognóstico é, na maioria dos casos, favorável. O objetivo deste artigo é relatar um caso de DMPB num indivíduo adulto, alertando para a possibilidade deste diagnóstico nesta faixa etária.

Descrição do caso: Apresenta-se o caso de um homem de 35 anos, com antecedentes de obesidade, rinite alérgica e história de varicela na infância, que recorreu à sua médica de família por pápulas pruriginosas nas palmas das mãos bilateralmente, associadas a odinofagia ligeira. Referia também ter estado em casa a cuidar do filho de 15 meses, com diagnóstico de DMPB, há cerca de sete dias. Assumiu-se o diagnóstico clínico de DMPB e foi tratado de forma sintomática. Dois dias depois regressou por extensão do exantema às plantas dos pés e à região perioral, tendo sido mantidos os cuidados. Na reavaliação, uma semana depois, apresentava descamação da pele das palmas das mãos e plantas dos pés e onicomadese das unhas das mãos e dos pés, sem surgimento de novas lesões. Considerou-se o quadro clínico em resolução e foram explicadas medidas de suporte e prevenção de contágio e recorrência.

Comentário: A DMPB ocorre de forma esporádica em adultos. Nesta faixa etária, a doença acomete mais frequentemente indivíduos do sexo masculino e a atopia é considerada um fator de risco. O curso da doença é maioritariamente autolimitado, com resolução em sete a dez dias, sendo suficiente o tratamento de suporte. Apesar de raras, em determinadas populações as complicações associadas à DMPB podem condicionar risco de vida, o que juntamente com a sua elevada contagiosidade implica uma atitude clínica atenta e um diagnóstico precoce para prevenção da sua disseminação. Assim, perante um doente adulto que apresente início abrupto de exantema maculopapular das palmas das mãos e plantas dos pés, o diagnóstico de DPMB deve ser considerado.

Palavras-chave: Doença mão-pé-boca; Exantema viral; Adulto imunocompetente.

\section{INTRODUÇÃO}

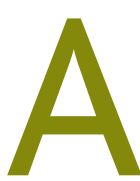
doença mão-pé-boca (DMPB) é uma infeção aguda autolimitada, de etiologia vírica, causada mais frequentemente por vírus da família coxsackievirus $(\mathrm{CV})$ e enterovírus (EV). ${ }^{1-2}$ Embora estejam mais frequentemente implicados o CVA16 e o EV71, outros vírus coxsackie A, como CVA6,

1. Assistente de Medicina Geral e Familiar. Unidade de Saúde da Ilha Terceira, Centro de Saúde da Praia da Vitória. Praia da Vitória, Açores, Portugal.

2. Médica Interna de Medicina Geral e Familiar. Unidade de Saúde da Itha Terceira, Centro de Saúde de Angra do Heroísmo. Angra do Heroísmo, Açores, Portugal.

3. Médica Interna de Medicina Geral e Familiar. Unidade de Saúde da Ilha Terceira, Centro de Saúde da Praia da Vitória. Praia da Vitória, Açores, Portugal.
CVA9 e CVA10, podem também estar associados a esta patologia. ${ }^{1,3}$

É uma doença exantemática muito frequente na infância, sobretudo nos primeiros cinco anos de vida, podendo, no entanto, atingir também adultos, mais frequentemente imunodeprimidos. ${ }^{1,4-5}$ Embora cerca de $11 \%$ dos adultos expostos fiquem infetados, menos de $1 \%$ desenvolve manifestações clínicas da doença. ${ }^{1}$ Quando ocorre no adulto imunocompetente, deve-se suspeitar do envolvimento de uma estirpe mais virulenta, como o CVA6. ${ }^{1-2}$

A doença acomete mais frequentemente indivíduos do sexo masculino. ${ }^{1,6}$ Outros fatores associados são: 
residência em meio rural ou outros meios de elevada densidade populacional, condições higieno-sanitárias precárias, populações migrantes, manipulação oral de brinquedos e baixo rendimento familiar. ${ }^{4} \mathrm{~A}$ atopia é considerada um fator de risco para o aparecimento da doença em adultos. ${ }^{2}$

A DMPB é altamente contagiosa entre crianças, contrariamente ao que se verifica em idade adulta. ${ }^{2} \mathrm{~A}$ transmissão é maior durante a primeira semana da doença pelo contato próximo com o indivíduo doente, com as suas fezes, secreções ou com objetos manipulados pelo mesmo. A fase de contágio dura até ao desaparecimento das lesões vesiculo-bolhosas, pelo que o evitamento ocupacional deve ser mantido até à resolução completa destas. ${ }^{1,7}$ Sabe-se também que o vírus é excretado nas fezes por várias semanas, ${ }^{1,4}$ pelo que é muito importante a adoção de medidas que diminuam o risco de contaminação dos conviventes, bem como de pessoas que prestem cuidados ou partilhem espaços com o doente. ${ }^{4,7}$

O curso da doença é maioritariamente autolimitado, com resolução entre sete a dez dias, pelo que o tratamento de suporte é suficiente. ${ }^{1,8}$

Estudos sugerem uma forte associação entre o aparecimento desta patologia e as mudanças climáticas, verificando-se uma maior incidência na Primavera e no Verão. ${ }^{1,4} \mathrm{~A}$ exceção é a doença causada pelo CVA6 que, por sua vez, parece ocorrer com maior frequência no Inverno. ${ }^{2}$

O quadro clínico típico caracteriza-se pelo aparecimento de um enantema oral doloroso, seguido de lesões cutâneas nas palmas das mãos e plantas dos pés, de morfologia, tamanho e cor variáveis. ${ }^{2,8} \mathrm{Em} 75 \%$ dos casos o doente apresenta concomitantemente um enantema e exantema e somente $10 \%$ apresenta apenas um dos dois. ${ }^{9}$

Os sintomas prodrómicos geralmente estão ausentes, mas podem incluir febre baixa, sintomas respiratórios altos, dor abdominal, vómitos e diarreia. ${ }^{2}$ Os casos relacionados com o CVA6 tendem a ter uma apresentação clínica atípica e mais agressiva, com distribuição mais generalizada das lesões, incluindo tronco e nádegas. ${ }^{1,6,10} \mathrm{~A}$ apresentação clínica atípica e o facto de a doença ocorrer mais em crianças pode ser um fator determinante no atraso do diagnóstico nos adultos, podendo muitas vezes ser erradamente diagnosticada como outra doença infeciosa exantemática ou reação alérgica. ${ }^{2,5-6,11}$

O seu diagnóstico é sobretudo clínico, através da observação de sinais como a febre e as lesões características nas mãos, pés e boca. ${ }^{1-2} \mathrm{~A}$ confirmação laboratorial do diagnóstico é realizada recorrendo ao isolamento e identificação do vírus, através da reverse transcription polymerase chain reaction ou indirect immunofluorescent assay, com amostra colhida por zaragatoa da orofaringe e de, pelo menos, duas vesículas e/ou por zaragatoa retal, principalmente em utentes que não apresentem vesículas, ou através da identificação de anticorpos neutralizadores do vírus no soro dos pacientes. ${ }^{1-2,5-6,12}$ No entanto, na maioria dos casos o recurso a estes exames é dispensável, quer pelo custo acrescido quer pela falta de acessibilidade ao exame [sobretudo em cuidados de saúde primários (CSP)] quer pelo prognóstico favorável da doença. ${ }^{5,12}$

As complicações desta patologia devem ser tidas em conta e poderão apresentar-se desde desidratação ou sobreinfeção bacteriana até meningite, encefalite ou miocardite. ${ }^{6,8}$ Apesar de raras, em determinadas populações, como em indivíduos imunodeprimidos ou recém-nascidos, as complicações associadas à DMPB podem condicionar risco de vida. ${ }^{7-8}$ Por se tratar de uma doença tipicamente benigna, de curso autolimitado e sem complicações ou sequelas frequentes, ainda não foi desenvolvida uma vacina. ${ }^{6}$

O tratamento da DMPB é sintomático e o prognóstico é, na maioria dos casos, favorável, com tendência à cura espontânea, sem sequelas, crosta ou cicatrizes, no período de sete a dez dias. ${ }^{1-2,5}$ No entanto, pela diversidade de vírus que podem estar na sua génese, a ocorrência de infeção não confere imunidade, pelo que pode haver uma recorrência do quadro ou reinfeção. ${ }^{12}$

O objetivo deste artigo é relatar um caso de DMPB num indivíduo adulto imunocompetente, alertando para a possibilidade deste diagnóstico numa faixa etária de atingimento menos frequente e contribuir para a celeridade diagnóstica e evicção de sobremedicação

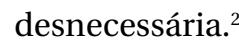

\section{DESCRIÇÃO DO CASO}

Apresenta-se o caso de um homem de 35 anos de idade, caucasiano. Natural e residente no concelho da Praia da Vitória. Tinha o $12^{\circ}$ ano de escolaridade e 


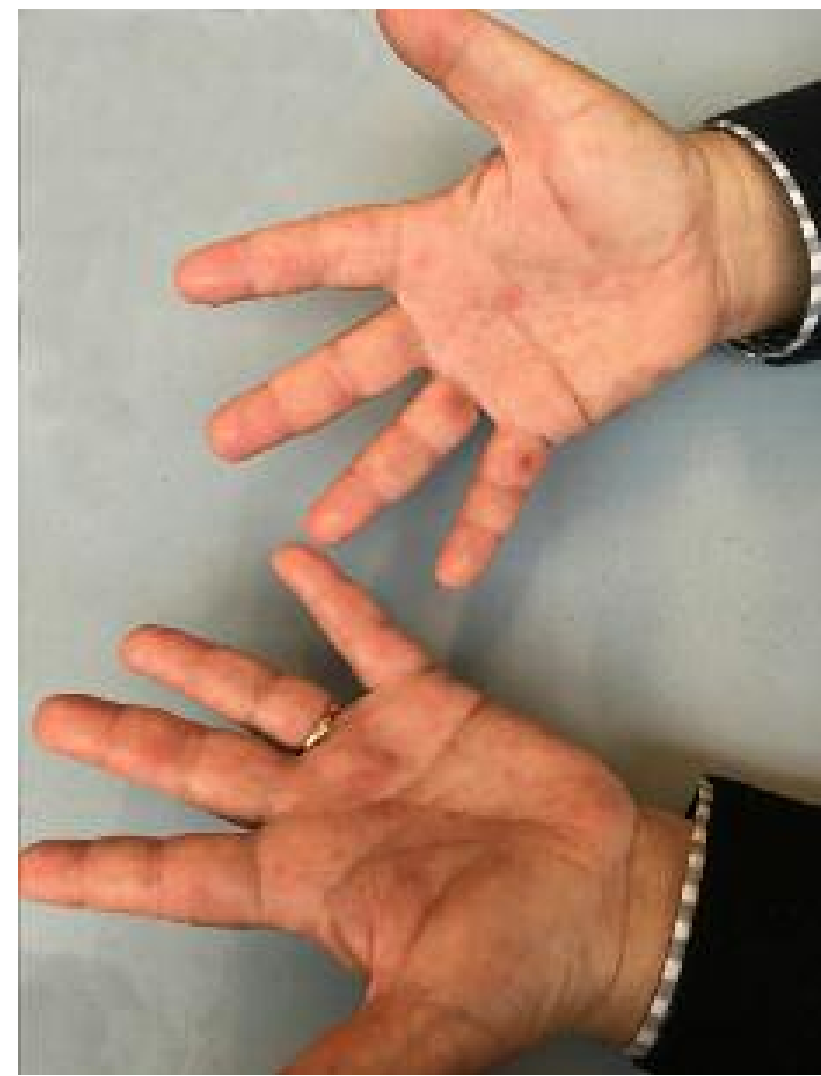

Figura 1. Exantema inicial nas palmas das mãos.

trabalhava como assistente técnico. Era casado e pertencente a uma família nuclear na fase II do ciclo de $\mathrm{Du}$ vall, de classe social média-alta, segundo o Índice de Graffar.

Como antecedentes pessoais apresentava obesidade de grau III, rinite alérgica e história de varicela aos cinco anos de idade, sem outros antecedentes médicos ou cirúrgicos. Não tinha necessidade de medicação crónica e negava alergias medicamentosas conhecidas.

Recorreu à sua médica de família, de forma não programada, por quadro de pápulas pruriginosas nas palmas das mãos bilateralmente, com dois dias de evolução, associadas a odinofagia ligeira. Sem febre objetivada, alteração do padrão alimentar ou de produtos de uso diário, sem toma de medicamentos e outros sinais ou sintomas. Referia ter o plano nacional de vacinação atualizado e negava viagens recentes, contacto com doenças potencialmente contagiosas e comportamentos de risco para doenças sexualmente transmissíveis

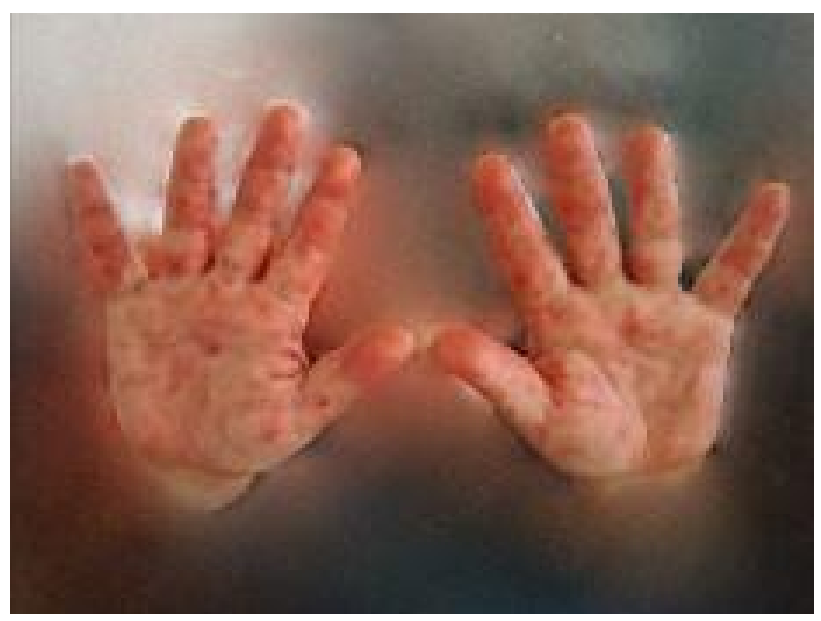

Figura 2. Exantema inicial nas palmas das mãos.

(DST). Referia também ter estado em casa a cuidar do filho de 15 meses, com diagnóstico de DMPB, há cerca de sete dias.

Ao exame físico constatavam-se pápulas circulares, de cerca de cinco milímetros de maior diâmetro, associadas a lesões de coceira nas palmas das mãos (Figura 1). No exame da orofaringe observava-se ligeira hiperemia dos pilares amigdalinos e petéquias do palato mole.

Foi considerado como diagnóstico mais provável o de DMPB, tendo em conta a apresentação clínica e o contexto epidemiológico. Foi aconselhada a evicção laboral e o contacto com os coabitantes, o reforço da higiene oral e das mãos, a desinfeção frequente de objetos utilizados, a alimentação leve e sem comidas ácidas ou salgadas. Foi medicado com bilastina $20 \mathrm{mg}$ de $12 / 12 \mathrm{~h}$, paracetamol $\mathrm{lg}$ de $8 / 8 \mathrm{~h}$, se febre ou dor, e adicionalmente ibuprofeno $400 \mathrm{mg}$ de $8 / 8 \mathrm{~h}$, caso a sintomatologia persistisse, com paracetamol isoladamente, aconselhado repouso, reforço da hidratação oral e a vigilância de sinais e sintomas de agravamento até à reavaliação clínica três dias depois. ${ }^{1,13-14}$

Dois dias depois regressou ao centro de saúde por agravamento do exantema nas palmas das mãos ( $\mathrm{Fi}-$ gura 2) e com extensão às plantas dos pés e à região perioral.

O exame físico mantinha-se sobreponível, à exceção de temperatura subfebril $\left(37,4{ }^{\circ} \mathrm{C}\right.$ de temperatura auricular) e extensão das lesões às plantas dos pés (Figura 3 ) e região perioral (Figura 4). 


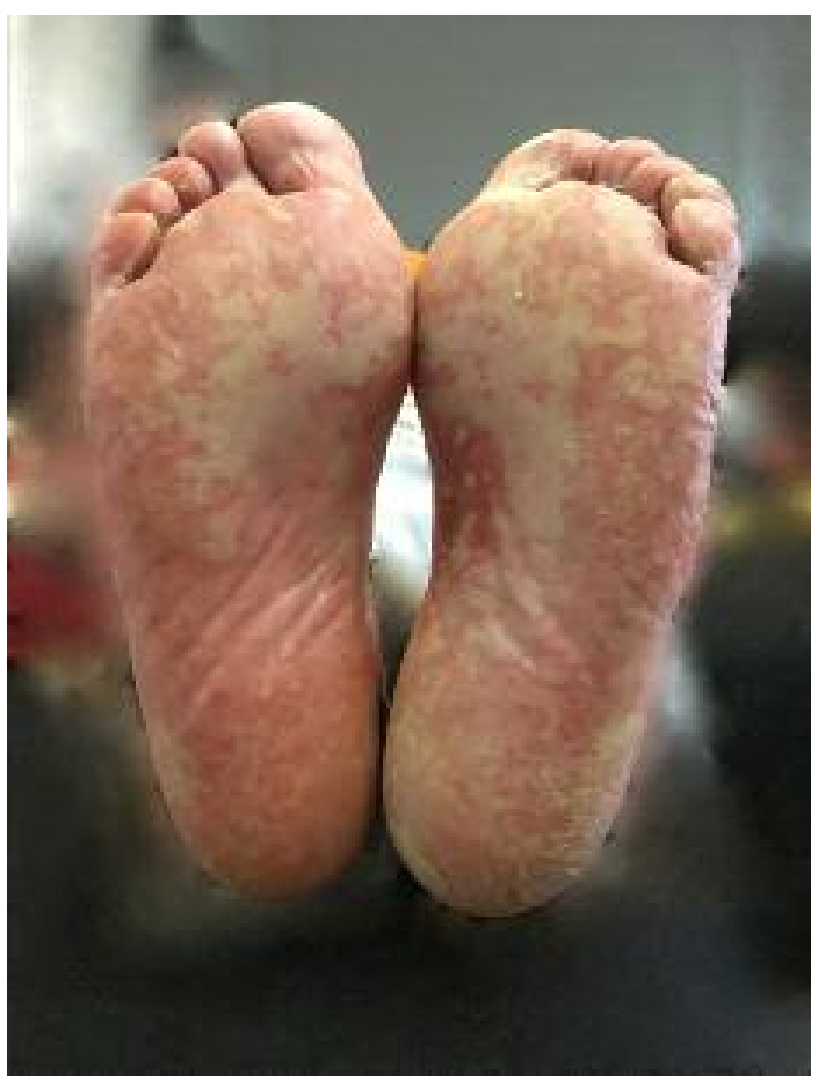

Figura 3. Exantema perioral.

Embora se mantivesse como diagnóstico mais provável a DMPB, solicitaram-se análises laboratoriais para exclusão de diagnósticos alternativos. O doente foi tranquilizado, foram mantidos o tratamento e as recomendações anteriores.

Foi reavaliado uma semana depois, referindo melhoria do prurido e sem queixas de novo. Ao exame físico, o doente encontrava-se apirético e notava-se destacamento da epiderme das palmas das mãos e plantas dos pés (Figura 5) e onicomadese das unhas das mãos e pés, sem surgimento de novas lesões. Os resultados analíticos revelaram leucocitose ligeira, sem alterações nas restantes linhagens, proteína $C$ reativa de $6,8 \mathrm{mg} / \mathrm{L}$, velocidade de sedimentação de $26 \mathrm{~mm}$, VDRL negativo e serologias virais para o vírus da imunodeficiência humana (VIH) 1 e 2 negativas.

Assumiu-se quadro clínico em resolução e foram mantidas as medidas de suporte e prevenção de contágio e recorrência, como a evicção de contacto com pessoas doentes.

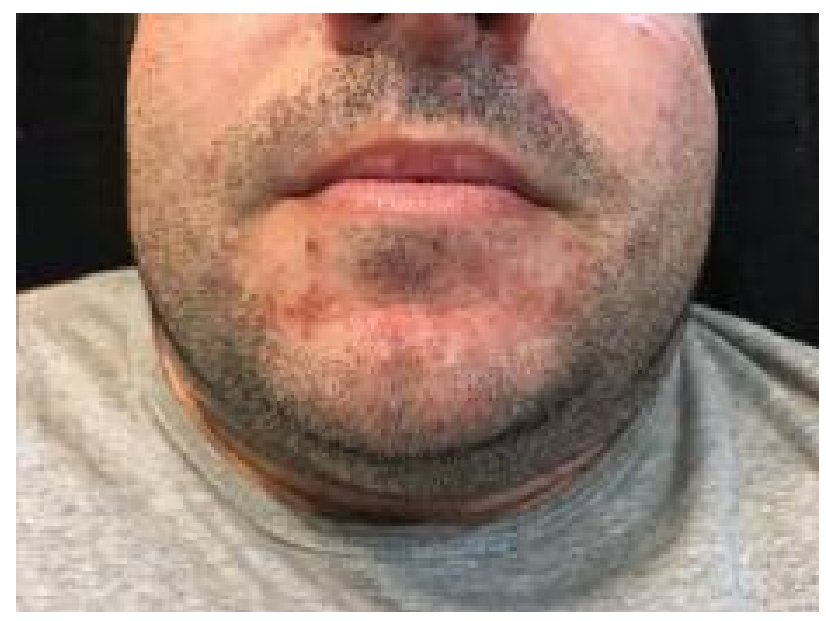

Figura 4. Exantema nas plantas dos pés.

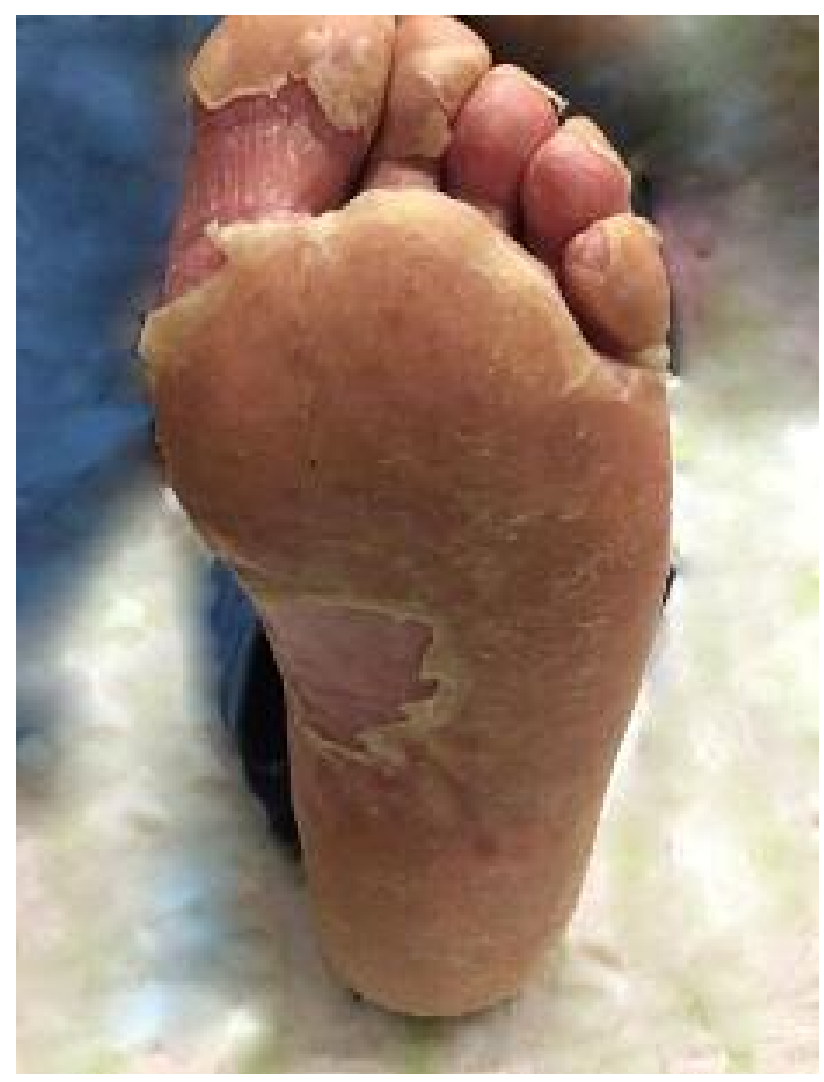

Figura 5. Fase descamativa na planta do pé.

\section{COMENTÁRIO}

Neste artigo apresenta-se o caso de um adulto com apresentação clínica típica de DMPB. Tratava-se de um doente do sexo masculino, com um quadro clínico de 
início na Primavera, que apresentava também história de atopia e contacto com uma criança diagnosticada com DMPB, fatores estes que estão descritos como preditores positivos para o seu diagnóstico, apesar da idade atípica. ${ }^{1,4,6,13}$ Como previsto na história natural da doença, o doente desenvolveu hiperemia e petéquias no palato e exantema pruriginoso nas mãos nas primeiras 48 horas, após provável contágio a partir do filho diagnosticado com DMPB e com evolução progressiva nos dias seguintes..$^{1,4,14} \mathrm{~A}$ fase descamativa e de onicomadese, que surgiram ao sétimo dia no doente apresentado, também foram descritas em relação a infeção por CVA6. ${ }^{1,6}$ O diagnóstico desta entidade é essencialmente clínico, sendo que este caso reforça a importância da investigação do contexto epidemiológico do indivíduo. Embora seja dispensável, tendo em conta a elevada probabilidade diagnóstica pela apresentação clínica típica e o contexto epidemiológico suspeito, o curso tipicamente autolimitado e sem necessidade de terapêutica dirigida e a falta de acessibilidade aos testes necessários em tempo útil nos CSP, o diagnóstico laboratorial é a confirmação absoluta da doença e da estirpe viral envolvida. ${ }^{1,5,15}$ Nos casos em que a avaliação analítica se justifica pela evolução desfavorável do caso podem ser incluídos parâmetros para avaliação da gravidade analítica da infeção, de imunodeficiência adquirida e de diagnóstico alternativos com serologias virais e pesquisa de sífilis, como foi o caso. ${ }^{12}$

O diagnóstico diferencial deve incluir a gengivo-estomatite herpética, varicela, sífilis secundária e outros exantemas virais, sendo a apresentação clínica e o contexto epidemiológico os principais diferenciadores. A gengivo-estomatite herpética, apesar de poder ser considerada pelo enantema, torna-se pouco provável, uma vez que neste caso há envolvimento concomitante das palmas e plantas, o que não acontece nesta patologia. A varicela pode manifestar-se também por um exantema maculopapular; contudo, geralmente as palmas das mãos e plantas dos pés são poupadas e as lesões normalmente apresentam-se em diferentes estadios de evolução simultaneamente. Além disso, o facto de o indivíduo já ter tido varicela em criança torna este diagnóstico ainda menos provável. A sífilis secundária caracteriza-se por um exantema maculopapular disseminado, não pruriginoso, que tende a envolver as palmas da mãos e plantas dos pés. Esta DST é uma das causas mais frequentes de úlceras orais e exantemas palmo-plantares em adultos, pelo que deve ser sempre considerada uma vez que o tratamento específico evita a evolução para outro tipo de complicações associadas à sífilis terciária. Como tal, adultos com lesões aftosas e/ou exantemas palmo-plantares, sem contexto epidemiológico sugestivo de outra etiologia, devem ser questionados quanto à presença de fatores de risco para DST e excluir a possibilidade de infeção sifilítica através do teste de VDRL, facilmente obtido em CSP. O facto de o indivíduo não ter comportamentos sexuais de risco nem aparente clínica de sífilis primária prévia tornam esta hipótese menos provável, o que acaba por ser excluída com um VDRL negativo. . $-2,5,16-19^{-19}$

Em CSP, onde não é possível um diagnóstico confirmatório imediato, as hipóteses de diagnóstico são geradas perante a história clínica e o exame físico do doente, obedecendo a uma hierarquia de probabilidades para as mesmas. A continuidade de cuidados e a proximidade dos mesmos, possibilita, na maior parte dos casos, reavaliar o utente e as suas queixas com a brevidade necessária e em diferentes estadios da doença, tranquilizando o clínico e o utente, oferecendo uma maior segurança na abordagem, orientação e tratamento do mesmo perante um diagnóstico não imediato.

Neste caso, as queixas inespecíficas em idade atípica tornaram-se um verdadeiro desafio clínico, que foi minimizado pela existência de um forte contexto epidemiológico e pela relação de proximidade e acessibilidade que permitiu acompanhar de perto a evolução da doença e, por fim, assegurar um curso de doença benigno e compatível com o diagnóstico inicial mais provável. Perante um doente adulto, que apresenta exantema maculopapular de início abrupto das palmas das mãos e plantas dos pés, o diagnóstico de DMPB deve ser considerado.

\section{AGRADECIMENTOS}

O artigo não contempla seção de agradecimentos.

\section{REFERÊNCIAS BIBLIOGRÁFICAS}

1. Omaña-Cepeda C, Martínez-Valverde A, Sabater-Recolons MM, JanéSalas E, Marí-Roig A, López-López J. A literature review and case report of hand, foot and mouth disease in an immunocompetent adult. BMC Res Notes. 2016;9:165.

2. Šabović EK, Točkova O, UršičT, Žgavec B, Dolenc-Voljč M. Atypical hand, 
foot, and mouth disease in an adult patient: a case report and literature review.Acta Dermatovenerol ALP Pannonica Adriat. 2019;28(2):858.

3. Lott JP, Liu K, Landry ML, Nix WA, Oberste MS, Bolognia J, et al. Atypical hand-foot-mouth disease associated with coxsackievirus A6 infection. J Am Acad Dermatol. 2013;69(5):736-41.

4. Wang JF, Guo YS, Christakos G, Yang WZ, Liao YL, Li ZJ, et al. Hand, foot and mouth disease: spatiotemporal transmission and climate. Int J Health Geogr. 2011;10:25.

5. Ramirez-Fort MK, Downing C, Doan HQ, Benoist F, Oberste MS, Khan $F$, et al. Coxsackievirus A6 associated hand, foot and mouth disease in adults: clinical presentation and review of the literature. J Clin Virol. 2014;60(4):381-6.

6. Wei SH, Huang YP, Liu MC, Tsou TP, Lin HC, Lin TL, et al. An outbreak of coxsackievirus A6 hand, foot, and mouth disease associated with onychomadesis in Taiwan, 2010. BMC Infect Dis. 2011;11:346.

7. Centers for Disease Control and Prevention. Hand, foot, and mouth disease [homepage]. Washington: CDC; 2020 [updated $2021 \mathrm{Feb} 2$ ]. Available from: https://www.cdc.gov/features/handfootmouthdisease/index.html

8. Murase C, Akiyama M. Hand, foot, and mouth disease in an adult. N Engl J Med. 2018;378:e20.

9. Modlin JF. Enterovirus and parechovirus infections: clinical features, laboratory diagnosis, treatment, and prevention. UpToDate [Internet]; 2018 Oct 25 [updated 2019 Nov 27]. Available from: https://www.uptodate.com/contents/enterovirus-and-parechovirus-infections-clinical-features-laboratory-diagnosis-treatment-and-prevention

10. Romero JR. Hand, foot, and mouth disease and herpangina. UpToDate [Internet]; 2018 Oct 10 [updated 2020 Feb 25]. Available from https://www.uptodate.com/contents/hand-foot-and-mouth-diseaseand-herpangina

11. Drago F, Ciccarese G, Broccolo F, Rebora A, Parodi A. Atypical hand, foot, and mouth disease in adults. J Am Acad Dermatol. 2017;77(2):e51-6.

12. World Health Organization Regional Office for the Western Pacific. A guide to clinical management and public health response for hand, foot and mouth disease [homepage]. Manila:WHO; 2011. Available from: https://iris.wpro.who.int/handle/10665.1/5521

13. Pintor E, Herreros B, Gargantilla P, Gutiérrez MJ. Hand, foot and mouth disease in an adult. Infection. 2018;46(3):437-8.

14. Lee CJ, Chen HC. Adult hand, foot, and mouth disease. Ear Nose Throat J. 2020;99(9):NP105-6.

15. Chiu WY, Lo YH, Yeh TC. Coxsackievirus associated hand, foot and mouth disease in an adult. QJM. 2016;109(12):823-4.

16. Dantas A, Oliveira MJ, Lourenço O, Coelho PB. Doença mão-pé-boca no adulto: a propósito de um caso clínico [Hand, foot and mouth disease in the adult: case report]. Rev Port Med Geral Fam. 2013;29(1):625. Portuguese

17. Pergam SA, Limaye AP. Varicella zoster virus (VZV) in solid organ transplant recipients. Am J Transplant. 2009;9(Suppl 4):S108-15.

18. Quintanilla-Gutiérrez E, Serrano-Collantes D. Dermatologia básica em medicina geral e familiar. Lisboa: LIDEL; 2011.

19. Dunmire SK, Hogquist KA, Balfour HH. Infectious mononucleosis. Curr Top Microbiol Immunol. 2015;390(Pt 1):211-40.

\section{CONFLITO DE INTERESSES}

Os autores declaram não possuir quaisquer conflitos de interesse.

\section{ENDEREÇO PARA CORRESPONDÊNCIA}

Mara Arruda

E-mail: maralbarruda@gmail.com

https://orcid.org/0000-0003-0777-5039

Recebido em 12-04-2020

Aceite para publicação em 18-09-2020 


\section{ABSTRACT}

\section{HAND-FOOT-MOUTH DISEASE IN ADULTS: TYPICAL PRESENTATION AT AN ATYPICAL AGE}

Introduction: Hand-foot-mouth disease (HFMD) is a self-limited, highly contagious, acute viral infection that occurs mainly in children. The typical clinical presentation is characterized by the appearance of painful oral enanthema, followed by cutaneous lesions on the palms and soles, of different morphology, size, and color. Its diagnosis is mainly clinical, the treatment is symptomatic, and the prognosis is, in most cases, favorable. The purpose of this article is to report a case of HFMD in an adult, alerting to the possibility of this diagnosis in this age group.

Case description: We present the case of a 35-year-old man with a history of obesity, allergic rhinitis, and varicella in his childhood, who presented to his family doctor with symptoms of pruritic papules on both hands and odynophagia. He also mentioned that he had been taking care of his 15-month-old son at home diagnosed with HFMD seven days before. A clinical diagnosis of HFMD was considered and he was treated symptomatically. Two days later, the exanthema extended to the feet soles and perioral region, and a week later the skin started to peel out, with the nails revealing onychomadesis. We assumed the disease was in remission and maintained supportive and prevention measures.

Comments: HFMD occurs sporadically in adults. In this age group, the disease affects more often males, and atopy is considered a risk factor for the onset of the disease in adults. The course of the disease is mostly self-limited, resolving in seven to ten days, being symptomatic treatment enough. Although rare, in certain populations, complications associated with HFMD can be life-threatening, which, associated with its high contagiousness, implies an attentive clinical attitude and an early diagnosis to prevent its spread. Thus, in the presence of an adult patient with an abrupt onset of maculopapular rash on the palms and soles, the diagnosis of DPMB should be considered.

Keywords: Hand-foot-mouth disease; Viral rash; Immunocompetent adult. 